\title{
Combating the Illegal Antiquity Trade through Museums and Economic Reform
}

\author{
Lindsay Williams
}

\begin{abstract}
A RChaeological looting has been present for the archaeological community. While many archaeologists are engaged in the complexity of the problem, the public is not. As part of the process for creating and implementing sustainable and realistic solutions, the issues and complexities need to be communicated to the public. For instance, in Jordan many looters are unaware of the economic disparity they are experiencing on the international antiquity market, or simply feel they are not in a position to do anything about it. These looters are searching for a way to support themselves and their community, and are either unaware or do not care about the damage the illegal antiquity trade has on the archaeological record. One of the easiest ways to communicate the harmful impact of looting to the Jordanian public is utilizing museums. However, this is only the first step as looters must be able to find a viable alternative to the loss of looting as a source of income. In this paper, I will explain the harmful effects of looting, both for the archaeological record and for looters, and offer more in-depth strategies for combatting the illegal antiquity trade in Jordan.
\end{abstract}

To identify and examine the different solutions available to combatting the illegal antiquity trade in Jordan, it is necessary to examine multiple disciplines. Some important areas to consider are economics, both the international and Jordanian antiquity market, and policy. It is only through a holistic approach that an understanding of the complexity of looting can be fully understood. To develop my understanding, I conducted literature reviews and drew upon my personal experiences in Jordan. To direct my research, I discussed the illegal antiquity trade with Dr. Adams, the Archaeologist leading the Barqa Landscape Project, which I was fortunate to take part in during the summer of 2019. My personal interest and knowledge in museum theory drew me to analyzing museums as a possible way to assist in combatting the illegal antiquity trade. Much of my research into the museums in Jordan was done through visits and analysis I did during my time in Jordan. As established public institutions, museums are able to bridge disciplines and effectively communicate the complexities of the antiquity trade in an engaging way. This led me to consider how else Jordanians may be educated in the antiquity trade, prompting analysis and research into the Jordanian education system. All together my thesis bridges multiple disciplines, including economics, policy, museums, and education.

Due to the complexities of the illegal antiquity trade and its impact on the lives of many Jordanians, I believe it is important to address my personal connection and bias. My education and interest in Archaeology has left me with an obvious bias towards conserving the archaeological record. I was incredibly aware from the beginning, due to my experiences in Jordan, that the illegal antiquity trade is not a simple issue, but instead one with various levels of complexity. So, it was important for me to arrive at a conclusion that provided a solution to the issue of the illegal antiquity trade. Additionally, I was determined to ensure that the needs of looters, and others who rely on the antiquity trade to make a living, were still addressed. It is important to address that firsthand perspectives from those who deal directly in the antiquity trade are absent from my piece. In order to create a more holistic view, I would have liked to speak to a looter or others directly involved in the 
trade. These considerations along with my personal experiences and views, guided the creation and direction of my discussion throughout my piece.

The illegal archaeological trade is not a new concept. Historically, western archaeologists have been accused of taking precious artifacts from countries during colonization or on explorative trips. In some cases, archaeologists have apologized and restored these objects to their countries of origin (Jennings, 2006). In other cases, western archaeologists are praised for their careful study and handling of these artifacts, as they have provided greater insight into the culture heritage in which they were found (Jennings, 2006). What has changed over the years is the respect for local heritage that has deepened as many of these countries, including Jordan, have developed a strong sense of local identity (Jennings, 2006). In all of these cases, archaeological study, past and present, stands apart from the current illegal trade due to its careful recording and study of the discovered objects in the context in which the objects were found.

Archaeologists are trained to carefully document the position of each artifact as it is found. When analyzing a site, it is crucial for an archaeologist to carefully consider the placement of an object and its relationship to other objects. This allows them to infer the potential purpose of each object. The context of an artifact may also be critical in determining how old an object is. These insights allow archaeologists to decipher the different components of an object to develop an understanding of the various parts of a culture they are studying. Context is a critical element of archaeology and is what makes ancient archaeological artifacts valuable, both for collectors and archaeologists. Ultimately, archaeological sites and artifacts are a non-renewable resource that archaeologists strive to protect and promote. Since looters typically lack archaeological training that allows them to understand the context of the artifacts, looting is incredibly harmful to the archaeological record.

Due to how harmful looting is to the archaeological record, looters are often judged harshly. Recently, however, academics who study looting have begun to refer to looters by other names deemed less judgmental. For example, Neil Brodie and Daniel Contreras (2012) in The Economics of the Looted Archaeological Site of Bâb edh-Dhrâ: A View from Google Earth, use the term "subsistence digger", as they recognize the larger social and political consequences of the illegal antiquity trade. A "subsistence digger" is defined as someone who uses the money earned from the sale of antiquities to support their traditional subsistence lifestyle (Brodie \& Contreras, 2012). The goal of changing the terminology used when referring to illegal antiquity traders is to avoid stigmatizing people or communities, who are trying to make a living in areas that may be economically deprived (Brodie \& Contreras, 2012). Subsistence diggers are aware that their area is rich in ancient artifacts which are heavily sought after internationally, and as a result, they see a way to make a living for themselves. Many of these diggers are unaware that they are selling items at a price substantially lower than the value of the artifacts on the international market (Brodie \& Contreras, 2012).

Much of the heritage legislation put in place to attempt to suppress the illegal excavation and trade of antiquities traditionally fails to recognize archaeology as an entity with any economic value (Brodie \& Contreras, 2012). The illegal antiquity trade continues to thrive, proving that this strategy is failing, as others are able to take advantage of the economic potential of artifacts (Brodie \& Contreras, 2012). The denial of the economic potential of archaeological heritage means there is little data on the economic aspect of archaeology: however, research conducted by Jerome Rose and Dolores Burke (2004) found that diggers in North Jordan received $\$ 7$ for each Roman oil lamp they found ${ }^{1}$. These lamps were then sold by dealers in London for $\$ 45$ each (Rose \& Burke, 2004). The diggers only received $15 \%$ of the final sale of the Roman oil lamps. In contrast, reports from Julie Hollowell (2006) found that diggers on St. Lawrence Island who had corporate ownership of the archaeological artifacts were making up to $70 \%$ of the final market value, when the artifacts entered the international market legally. According to Brodie and Contreras (2012), it is the risks associated with smuggling the archaeological artifacts that lead to the mark ups in price and low return for the Jordanian diggers. Brodie and Contreras (2012) also suggest that since the diggers are working illegally they may feel less cheated, due to a lack of legitimate employment. All of these findings reveal that Jordanian diggers are not making nearly

\footnotetext{
${ }^{1}$ There was no clarification in the article, but I believe these values were in American dollars, as the article was published in Washington, DC.
} 
as much money as they would if they were working in a legal trade market. The lack of recognition of the economic value of antiquities in legislation has allowed the black market to thrive, harming not only the cultural heritage of Jordan, but also the diggers who take part in the illegal antiquity trade.

One of the research programs that is working to combat the illegal archaeological trade is "Follow the Pots" (FTP). FTP is studying pots and grave goods found at Early Bronze Age cemeteries, specifically Fifa, Bab adh-Dhra', and en-Naqa/es-Safi in the Southern Ghor of Jordan (Kersel \& Chesson, n.d.). The FTP project looks at the "emergence of prehistoric urbanism and increasing social complexity in the Early Bronze Age of the southern Levant, and the multiple and contested values of this archaeological heritage to multiple stakeholders today" (Kersel \& Chesson, n.d.). FTP is studying how people, including looters, collectors, individuals living in the southern Ghor, museums, and government officials, associated with the pots and grave goods found at the aforementioned Early Bronze Age cemeteries operate in relation to the antiquity trade. This project views archaeological objects as having two lives: the first life is as grave goods, and the second as looted and excavated artifacts (Kersel \& Chesson, n.d.). To gain a deeper understanding of the use and possible reuse of Early Bronze Age artifacts, FTP is employing an integrated approach of ethnographic and archaeological methods (Kersel \& Chesson, n.d.). Ultimately this project strives to provide a "nuanced and balanced set of answers to the question 'Why Looting Matters?'" (Kersel \& Chesson, n.d.). FTP claims that looting continues to happen because archaeologists have not spent enough time on understanding how different individuals see value in archaeological artifacts (Kersel \& Chesson, n.d.). For example, Jordanian looters see archaeological objects as an economic resource. As FTP states on their website, "in the end, both looters and archaeologists excavate materials from the ground and send them along a path that removes them from their original context to be valued in one way or another" (Kersel \& Chesson, n.d.). The real difference between archaeologists and looters, as explained by the previous quotation, is

Having museums where the public is able to interact with objects directly is more impactful than sim- how they value the archaeological objects they find. Archaeologists focus more on the value of these objects for the archaeological record, whereas looters focus on the economic value.

FTP strives to minimize these differences by practicing "community archaeology" (Kersel \& Chesson, n.d.). "Community archaeology" is defined by FTP to be "archaeology by, and for, the people" with the key lying in ensuring that archaeologists are listening to the local population within the area they are working (Kersel \& Chesson, n.d.). The FTP team go beyond the practice of community archaeology to seriously consider the question "who owns the past?" (Kersel \& Chesson, n.d.). This is a very difficult question to answer. In many cases there are groups who claim to own the past that do not match the Jordanian law, which states, under Article 5 of Law no. 21 of 1988, "ownership of immovable antiquities shall be exclusively vested in the state" (Kersel \& Chesson, n.d.). FTP points to the rapid destruction of the archaeological record, including development, illegal activity, and an increased understanding of the need to protect cultural heritage, as motivation for attempting to answer this question (Kersel \& Chesson, n.d.). Recognizing the complexity of the differing values placed in archaeological objects by various parties is a crucial step in finding a solution to the issue of the illegal antiquity trade. The FTP program is an important stepping stone toward raising awareness among the academic community and the public on the various perspectives of archaeological looting.

It has proven difficult to get the general public of Jordan engaged in community archaeology and the issues of looting. As previously mentioned, many Jordanians participating in looting are either unaware, or simply do not care, about the consequences to themselves and others. So in an effort to make those who are unaware, aware of the consequences of looting, community engagement and education is crucial. One of the forms of engagement and education that Jordan is already taking advantage of is museums. Museums are an extremely valuable resource, especially in teaching the public about archaeology, as they allow the public to interact with and experience in-person the objects which archaeologists study.

ply relying on photos and the written word to convey the importance of archaeology for supporting a popu- 


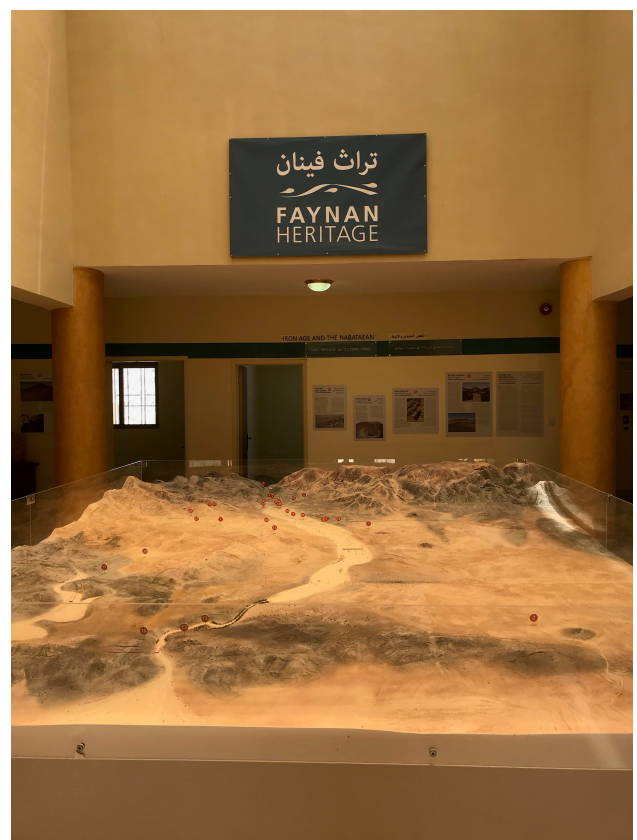

(a) Figure 1

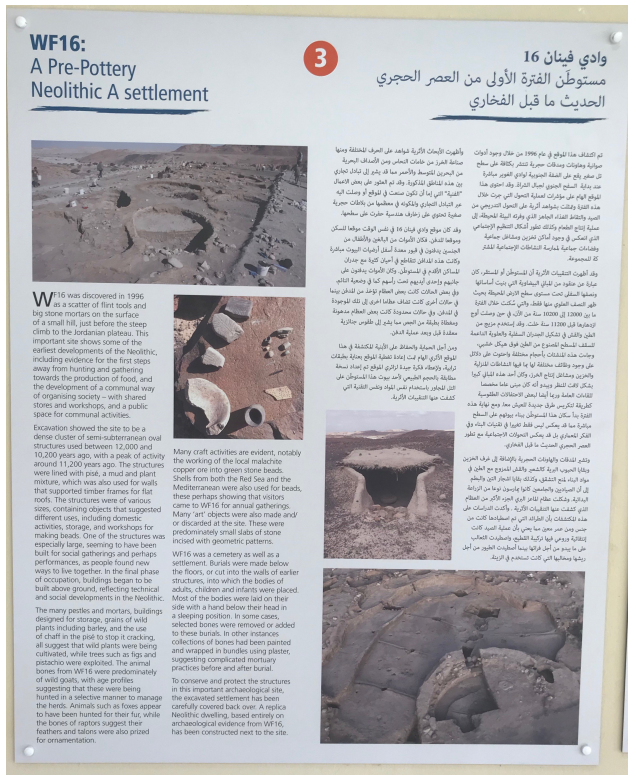

(b) Figure 2

Left: Replica of the Faynan landscape for "Discovering Faynan Heritage" (photo from personal collection). Right: Example of a didactic wall panel for the "Discovering Faynan Heritage" exhibit (photo from personal collection).

lation's cultural heritage. Object-centric learning experiences are what make museums stand out. Objectcentric learning capitalizes on the scale, authenticity, value, and resolution and density of information of objects, as a method for enhancing a learning experience (Blaine-Moares \& Gorbet, 2011). The resolution and density of information is typically known as how an object engages your five senses: what is the sound, texture, weight, and etcetera, of the object? Scale is another characteristic that is best displayed by a physical object. For example, seeing a Bronze Age Era pot in person will be much more impactful for an individual than trying to understand the scale on a photo. Otherwise, the individual looking at the object in an image is expected to have the training to understand the scale of the image which much of the public does not. In the case of archaeological objects, authenticity and value may be the most important characteristics. A great example is the bust of Nefertiti. Not only is the bust beautiful, but the meaning held in the object as a result of being connected to Nefertiti is extremely impactful in person. The bust's monetary value and the uniqueness of the bust's beauty immediately prompts a reaction from viewers. An object's characteristics, including the scale, authenticity, value, resolution, and density of information, suggest the uniqueness of object-centric learning found in museums. This is especially valuable in archaeology, as there are so many objects that can easily be displayed in a manner to effectively educate the public.

In Jordan there are many museums attempting to capitalize on object-centric learning. In the next section I will discuss three museums in Jordan that utilize object-centric learning: the Faynan Museum, the Jordan Archaeological Museum, and the Lowest Point on Earth Museum. These museums, while already well designed, with a few minor adjustments could be used more effectively as a method for combatting the illegal antiquity trade.

The Faynan Museum highlights the many archaeological discoveries of the nearby landscape. When I visited the museum in June of 2019, only the lobby of the museum was open, but it set the tone for the whole museum. The main exhibit is titled, 'Discovering Faynan Heritage', and features a replica of the nearby landscape with numbered notable locations (Fig. 1). Visitors can then trace the numbers displayed to the corresponding wall didactics (Fig. 2). Didactics are interpretive texts related to the display, 


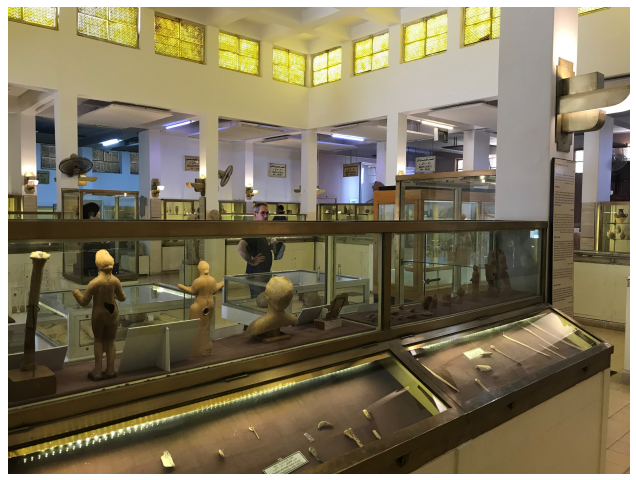

(a) Figure 3

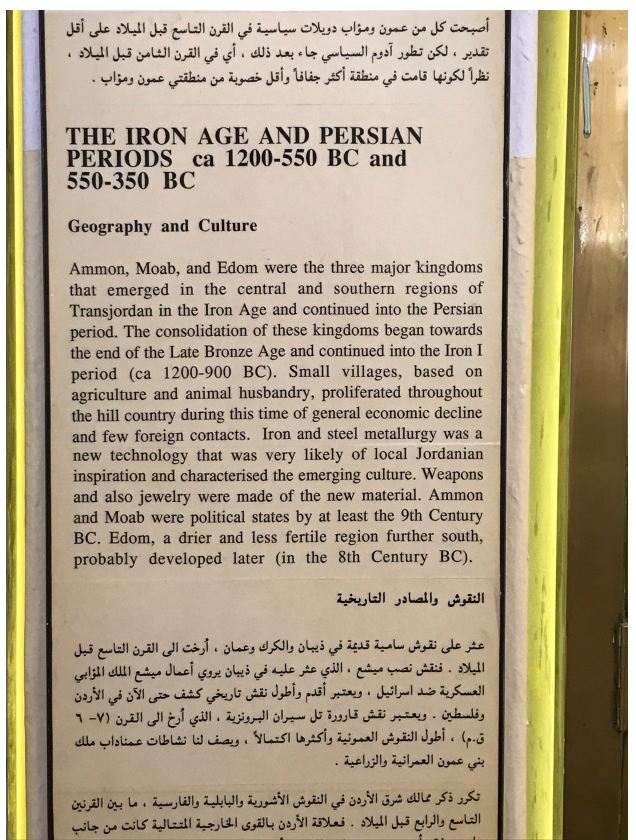

(b) Figure 4

Left: The Jordan Archaeology Museum, highlighting the display of objects (photo from personal collection). Right: A didactic at the Jordan Archaeology Museum, highlighting the use of both English and Arabic (photo from personal collection).

typically seen on exhibition walls or as a label beside an object. These didactics are in English and Arabic making them accessible to a wide audience. The replica allows viewers to gain a sense of scale of the area and orientate themselves to their location and the relative locations of various archaeological sites. This is very effective in allowing viewers to engage and relate to the archaeological sites. As a result, it creates a greater sense for the local community of the cultural heritage of the area they are in.

The Jordan Archaeology Museum takes full advantage of all of the elements of object-centric learning. The museum is filled with various archaeological objects from different eras collected from all over Jordan (Fig. 3). This museum does an excellent job of making many of the objects that would normally only be available to viewers in images, publicly accessible. For preservation purposes, many of the objects are held in glass containers and are not available for vis-

The Lowest Point on Earth Museum is located 1318 feet below sea level at Safi in Jordan and was opened on the 18th of May in 2012 (Hellenic Society for Near Eastern Studies, 2012). This museum itors to touch or physically interact with. However, even behind glass, the scale, value, and authenticity of the objects can be conveyed to the audience in an impactful way. With most of the artifacts displayed at the Jordan Archaeology Museum, there are accompanying didactics (Fig. 4). These didactics, like at the Faynan Museum, are presented in Arabic and English to target a wide number of visitors. However, these didactics are not as accessible to the general public. They contain a lot of language aimed at those with previous archaeological experience, such as the term metallurgy. In attempting to engage the general public with the archaeological objects presented, it would be more engaging to have these didactics written in simpler language and have definitions provided for those with little or no archaeological background. Overall, this museum is an exceptional place for tourists and locals alike to engage with archaeological objects.

is operated by the Ministry of Tourism and Antiquities and was set up in collaboration with the British Museum (Hellenic Society for Near Eastern Studies, 2012). The Lowest Point on Earth Museum takes 


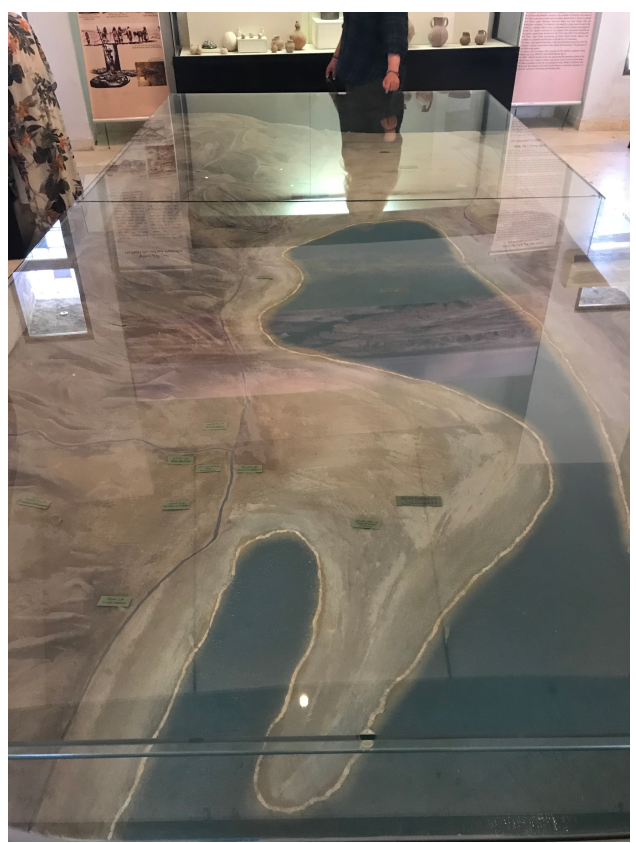

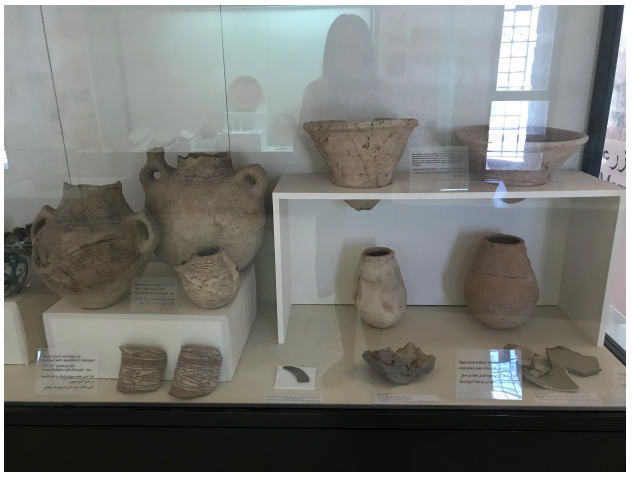

(b) Figure 6

(a) Figure 5

Left: Diagram of the landscape from the Lowest Point on Earth Museum (photo from personal collection). Right: Pottery on display at the Lowest Point on Earth Museum (photo from personal collection).

many of the best elements of the Archaeology Museum of Jordan and the Faynan Museum and brings them together. Right as you enter the museum there is a diagram of the surrounding landscape pointing out various archaeology sites that are referenced throughout the museum (Fig. 5). This map is not numbered, as the one at the Faynan Museum is, but instead uses the names of sites which viewers can refer back to as they explore the museum. The museum also has numerous archaeological objects on display with associated didactics, similar to those at the Archaeology Museum of Jordan (Fig. 6). What makes the Lowest Point on Earth Museum stand apart from the other two is the discussion on the need for conservation in archaeology. One of the largest features of the museum is a huge mosaic with an accompanying didactic explaining the need for mosaic conservation (Fig. 7). The mosaic alone directly conveys to visitors its authenticity and value in its size and presence

All of these museums are set up to cater to the local and tourist populations. An article highlighting the soft opening of the Faynan Museum discussed the support and engagement of the local school system in the opening of the museum (Palmer, n.d.). The abil- in the space. Behind the mosaic display is a window through which visitors can sometimes see archaeologists do conservation work on various archaeological objects. This is a smart addition to the museum because it allows for visitors to see the real-world application of what they are learning about. Another important didactic in the museum discusses the need for archaeological cooperation with local peoples in rescuing and preserving the cultural heritage unique to the area (Fig. 8). This is a direct example of how museums can be used to explain the value of preserving the archaeological record and why it matters to the local population. Adding in didactic wall panels discussing community archaeology, conservation, and/or the illegal antiquity trade is a simple step that all Jordanian archaeological museums could implement. Communicating this information is a valuable first step in combatting the illegal antiquity trade.

ity for teachers to utilize these museums as an educational resource will be incredibly helpful in engaging with local populations to understand the importance of archaeology. In my research, I was not able to find any specific information on the social studies 


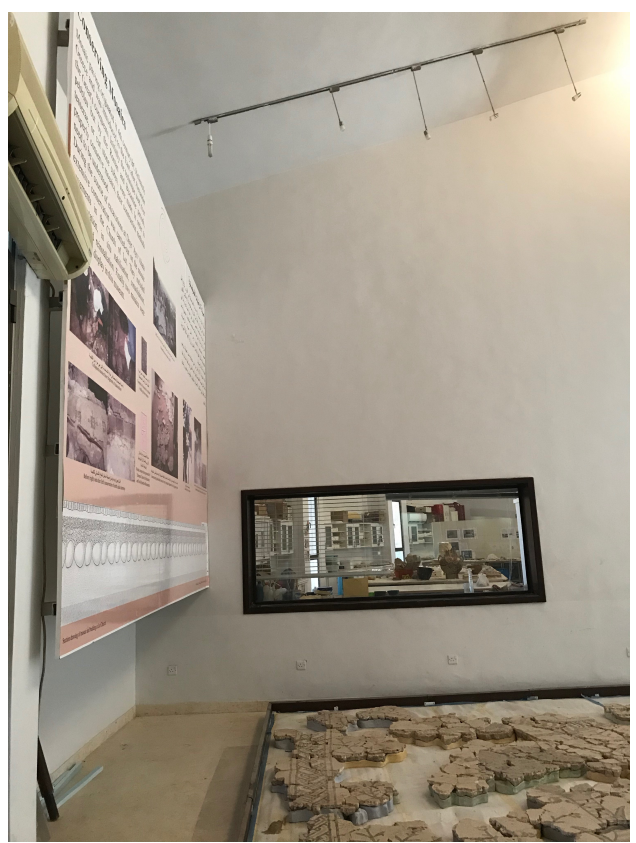

(a) Figure 7

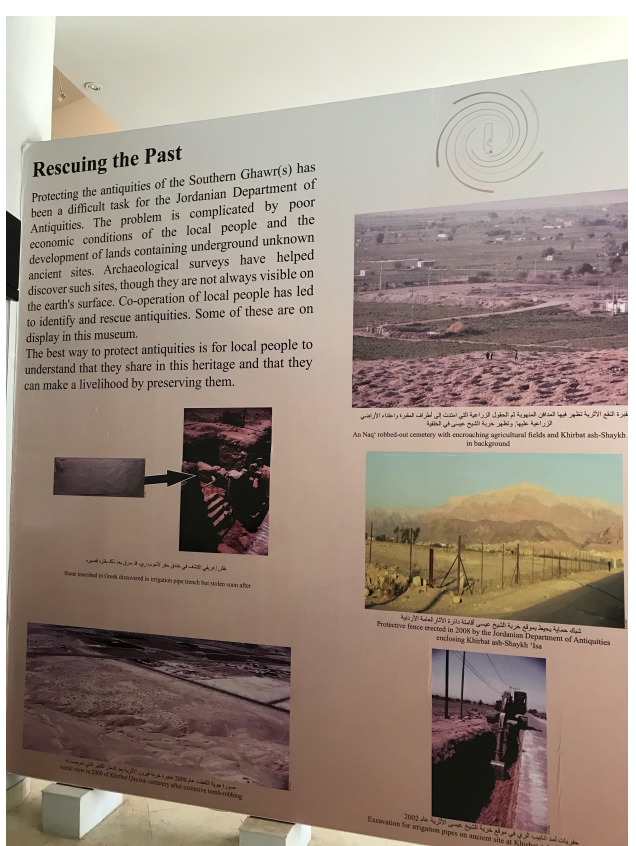

(b) Figure 8

Left: Mosaic display at the Lowest Point on Earth Museum (from personal collection). Right: Didactic wall panel discussing "Rescuing the Past" at the Lowest Point on Each Museum, also has an Arabic version not pictured (from personal collection).

curriculum, at any level, of the Jordanian education system. I did, however, find a general statement that says "the Jordanian social studies' curriculum is considered the developmental focus in all types and dimensions: The economic, social, cultural, technological, environmental, demographic, human, security, global, health, and future education" (Alelaimat \& Taha, 2012). Field trips to these museums and discussion on the illegal archaeological trade would fit directly into this description of the curriculum. Engaging young Jordanians in the archaeology of their country would be impactful, as it would start the conversation in local communities on the harm caused by the illegal antiquity trade. Understanding the value of the archaeology and the lack of relative economic

Due to the overwhelming complexities of the illegal antiquity trade, there is not one simple solution. Education, engagement, and communication with local communities through museums and other resources will start the process of combatting the illegal antiquity trade. However, to accompany the ideas being communicated there needs to be viable economic alternatives for those who are accustomed gain in the antiquity trade, starting at a young age, would be one strategy that helps to combat the illegal antiquity trade. Making small changes, such as more publicly accessible didactics, and more discussion of community archaeology, conservation, and the illegal antiquity trade, would ensure these museums could be used to their full potential. Engaging the older generations through demonstrations, local events, and lectures all hosted at the museums, would also be a fantastic way to communicate the importance of archaeology for preserving cultural heritage. This would take the object-centric learning that is unique to museums a step further and enhance the experience of both the local and tourist populations.

to making a living from the archaeological trade. As Roger Atwood (2004) said, "The biggest obstacle to stopping the looting of the ancient world is overcoming the feeling that it is inevitable ... [that] as long as there are rich buyers, there will always be poor looters willing to supply them." A solution he proposes is encouraging museums and governments to sell some of their interesting, but more common 
artifacts, fully documented, to dealers and collectors (Atwood, 2004). Full documentation would include key archaeological information such as where it was found and other important contextual information. The money made from these sales could be used to fund community archaeology projects and preservation efforts (Atwood, 2004). Selling these objects fully documented would set a high standard for future documentation, potentially making it harder for the black market to sell undocumented or inadequately documented artifacts (Atwood, 2004). Under the current system of heritage laws, which deny the economic value of archaeology, use of documentation would combat the unintended effects of these laws encouraging the black market (Atwood, 2004).

Another suggestion, to support those who rely on archaeology as an economic resource, from Lane Jennings (2006) would be to encourage museums and galleries to sell licensed reproductions. Modern crafts workers could be trained to recreate ancient artifacts, perhaps using traditional methods and materials, to market to tourists (Jennings, 2006). The Lowest Point on Earth Museum already sells crafts made by locals. Encouraging locals to adapt these practices and offering lectures and classes at the museums on how to create these objects would have a positive impact on the preservation of the archaeological record and the economy. Holding these classes and lectures at the museums, would also encourage locals to explore the exhibits and hopefully learn more about why archaeology is important. These crafted objects could be sold for a higher price than the $\$ 7$ that some looters are believed to be making from trading on the illegal antiquities market. This mobilization of the archaeological economy would effectively accompany an increase in communication on the value of archaeology for the cultural heritage of Jordan.

The question of "who owns the past" can often lead to a debate within the archaeological community about whether archaeological objects should leave their place of origin. Some archaeologists ar- gue that all archaeological objects found in a country should remain under the ownership of that country. As a result, many countries have enacted new laws, and archaeologists go through strict processes in order to be given permission to excavate; for example, Jordan's "Law No. 21 for the year 1988 - The Law of Antiquities" (Kersel \& Chesson, n.d.). There have been numerous debates over whether items collected, often during periods of colonization, and displayed in museums internationally, should be returned to their home of origin. My solutions do not address this issue. Instead I have chosen to focus on combatting the illegal antiquity trade in its existing form. Some archaeologists might argue that my solutions would further remove an object from its place of origin, by encouraging a legal antiquity market, which could be harmful for an artifact's cultural understanding and interpretation. However, with the increase in standards in the antiquity trade for full documentation, the interpretation and understanding of the artifacts place of origin would be improved. In the future, this could also allow for the object's return to its place of origin.

To effectively protect the archaeological record, museums and government officials should follow in the lead of "Follow the Pots" and work with local communities, collectors, looters, and dealers to create a legal antiquity market that stimulates the economy. This could be accomplished through the sale of replicas and surplus antiquities. However, to get to a point when this is possible there needs to be an increased awareness of the value of archaeology within Jordan. Jordan is fortunate to have many museums that could be capitalized upon to convey this information to the public. Archaeological objects are a non-renewable resource and efforts to promote their conservation are of the utmost importance. By partnering with local museums, public education on the value of archaeological resources can be communicated, and the creation of a legal antiquity market can be supported.

\section{Author Biography}

Lindsay Williams is going into her fourth year of Knowledge Integration at the University of Waterloo. In addition to her studies in Knowledge Integration, Lindsay is pursuing a minor in Anthropology and a Collaborative Design Specialization. Lindsay originally wrote this paper for her final research paper for an archaeological field school she took part in during the summer of 2019 in Jordan. She was working on the Barqa Landscape Project in the Wadi Faynan region. While in Jordan, Lindsay became interested in the 
illegal antiquity market and all of its complexities. A major part of the Knowledge Integration program is studying museums and museum theory. So, for her final paper she was excited to write about how museums could be used to help combat the issue of the illegal antiquity trade. Lindsay is incredibly grateful for all of the hard work of the editors at the Journal of Integrative Research and Reflection and for this opportunity. 


\section{Works Cited}

Alelaimat, A., \& Taha, K. (2012, November 30). Sustainable Development and Values Education in the Jordanian Social Studies Curriculum. Retrieved from https://eric.ed.gov/?id=EJ1033590

Atwood, R. (2004). Stealing History: Tomb Raiders, Smugglers, and the Looting of the Ancient World. St. Martin's Press.

Blain-Moraes, S. and Gorbet, R. (2011). Museums as Object-Centric Learning Experiences.

Brodie, N. and Contreras. D. (2012). The Economics of the Looted Archaeological Landscape of Bab edh Dhra': A View from Google Earth. All the King's Horses. Essays on the Impact of looting and the Illicit Antiquities Trade on our Knowledge of the Past. Washington DC: The SAA Press: 9-24. Retrieved from https://www.researchgate.net/ profile/Daniel_Contreras3/publication273658315_The_economics_of_the_looted_archae ological_site_of_Bab_edhDhra'_a_view_from_Google_Earth/links/56a5d4a008aeef24c5 8d9c27/The-economics-of-the-looted-archaeological-site-of-Bab-edh-Dhra-a-view-fromGoogle-Earth.pdf

Hellenic Society for Near Eastern Studies. (2012). The Museum at the Lowest Place on Earth at Safi in Jordan officially opened its doors on 18 May 2012. Retrieved from http://www.hsnes.org/news_item002.htm

Jennings, L. (2006). Raiding the Past: What future for antiquities. The Futurist, 40(3), 8-9. Retrieved from https://search-proquest-com.proxy.lib.uwaterloo.ca/docview/218574089/fulltextPDF/5158B38AA5D947E8PQ/1?accountid=14906

Kersel, M. M., \& Chesson, M. S. (n.d.). Follow the Pots Project. Retrieved from https://followthepot sproject.org/

Palmer, C. (n.d.). Faynan Museum Soft Opening, 4 March 2018 - an 'archaeological celebration'. Retrieved from https://cbrl.ac.uk/news/item/name/faynan-museum-soft-opening-4-march-2018-an-archaeological-celebration

Rose, J. C., \& Burke, D. L. (2004). Making money from buried treasure. Culture Without Context, (14), 4-8. Retrieved from https://traffickingculture.org/app/uploads/2012/07/CWC-14.pdf. 